\title{
Uncertainty in the spatial distribution of tropical forest biomass: a comparison of pan-tropical maps
}

Edward TA Mitchard ${ }^{*}$, Sassan S Saatchi ${ }^{2}$, Alessandro Baccini ${ }^{3}$, Gregory P Asner ${ }^{4}$, Scott J Goetz ${ }^{3}$, Nancy L Harris ${ }^{5}$ and Sandra Brown ${ }^{5}$

\begin{abstract}
Background: Mapping the aboveground biomass of tropical forests is essential both for implementing conservation policy and reducing uncertainties in the global carbon cycle. Two medium resolution (500 m - $1000 \mathrm{~m}$ ) pantropical maps of vegetation biomass have been recently published, and have been widely used by sub-national and national-level activities in relation to Reducing Emissions from Deforestation and forest Degradation (REDD+). Both maps use similar input data layers, and are driven by the same spaceborne LiDAR dataset providing systematic forest height and canopy structure estimates, but use different ground datasets for calibration and different spatial modelling methodologies. Here, we compare these two maps to each other, to the FAO's Forest Resource Assessment (FRA) 2010 country-level data, and to a high resolution (100 m) biomass map generated for a portion of the Colombian Amazon.
\end{abstract}

Results: We find substantial differences between the two maps, in particular in central Amazonia, the Congo basin, the south of Papua New Guinea, the Miombo woodlands of Africa, and the dry forests and savannas of South America. There is little consistency in the direction of the difference. However, when the maps are aggregated to the country or biome scale there is greater agreement, with differences cancelling out to a certain extent. When comparing country level biomass stocks, the two maps agree with each other to a much greater extent than to the FRA 2010 estimates. In the Colombian Amazon, both pantropical maps estimate higher biomass than the independent high resolution map, but show a similar spatial distribution of this biomass.

Conclusions: Biomass mapping has progressed enormously over the past decade, to the stage where we can produce globally consistent maps of aboveground biomass. We show that there are still large uncertainties in these maps, in particular in areas with little field data. However, when used at a regional scale, different maps appear to converge, suggesting we can provide reasonable stock estimates when aggregated over large regions. Therefore we believe the largest uncertainties for REDD+ activities relate to the spatial distribution of biomass and to the spatial pattern of forest cover change, rather than to total globally or nationally summed carbon density.

Keywords: Aboveground biomass, Carbon, Data inter-comparison, Maxent, Random forest, REDD, REDD+, Remote sensing, Tropical forests, UNFCCC

\footnotetext{
* Correspondence: edward.mitchard@ed.ac.uk

${ }^{1}$ School of GeoSciences, University of Edinburgh, Crew Building, The King's Buildings, Edinburgh EH9 3JN, UK

Full list of author information is available at the end of the article
}

\section{Biomed Central}

(c) 2013 Mitchard et al.; licensee BioMed Central Ltd. This is an open access article distributed under the terms of the Creative Commons Attribution License (http://creativecommons.org/licenses/by/2.0), which permits unrestricted use, distribution, and reproduction in any medium, provided the original work is properly cited. 


\section{Background}

The clearing of tropical forests and their conversion to other land uses has resulted in gross emissions of $0.45-$ 1.7 Pg C year $^{-1}$ (90\% prediction interval) from 20002007 , equivalent to $5-19 \%$ of global anthropogenic $\mathrm{CO}_{2}$ emissions [1-3]. Intact tropical forests are, however, thought to be serving as a carbon sink of similar magnitude, capturing an estimated 0.55-1.49 $\mathrm{Pg} \mathrm{C}_{\text {year }}{ }^{-1}$, equivalent to $6-17 \%$ of anthropogenic $\mathrm{CO}_{2}$ emissions, over the same period [2]. While there are many other reasons to protect tropical forests, the preservation of their carbon stocks and their potential as a future carbon sink has motivated a policy priority among the international community for their protection in order to reduce greenhouse gas (GHG) emissions, with associated benefits to society provided by their ecosystem services [4].

Many different schemes have been pursued to conserve tropical forests, but all rely on the quantification of stored carbon stocks to allow a calculation of avoided GHG emissions. The UN Framework Convention on Climate Change (UNFCCC) initiative "Reducing Emissions from Deforestation and forest Degradation" (REDD+, [5]) may create both social and economic incentives for conservation of forests in tropical countries. At an international level, REDD+ remains in negotiation within the UNFCCC, with the goal to include REDD+ in the next global climate change agreement. However, pilot and preparatory activities are already occurring at a national level, largely funded by UN-REDD (a consortium of the FAO, UN and UNEP), the Forest Carbon Partnership Facility (World Bank), and individual governments, especially Norway [6]. Parallel to the main REDD+ process, Norway has set up bilateral deals with Brazil, Guyana, Indonesia and Tanzania that allow for the transfer of up to US\$1 billion for conservation and development, in return for the countries meeting targets for reducing deforestation rates [7]. Furthermore there are already many voluntary REDD+ projects, generating credits primarily under the Verified Carbon Standard (VCS), with total REDD+ credit sales equal to $\$ 85$ million in 2010 [8]. These projects are increasing in number, meaning that there is already some implementation of REDD+ in many tropical forest regions.

Under the UNFCCC, countries planning to participate in the REDD+ mechanisms are required to use the Intergovernmental Panel on Climate Change (IPCC) GHG accounting framework for estimating their anthropogenic emissions caused by deforestation and forest degradation [9]. One of the key inputs into the IPCC framework is the carbon stocks of the forests undergoing change. The difference between the pre- and post- deforestation or degradation carbon stocks is the 'emission factor', which is the carbon emissions per unit area due to forest cover change. The product of the emission factor and the area of forest change provides the estimate of the total carbon emissions.
Countries participating in a future UNFCCC agreement will likely need to assess and monitor their carbon stocks regardless of their inclusion in REDD+. One approach often followed to obtain carbon stock estimates is to map vegetation types within a landscape and assign a carbon density value to each vegetation type, using either international or locally-derived values from fieldbased inventory [9]. However this method can have high uncertainty, especially over large areas or when using generic carbon density values, so to maximise potential financial benefits countries may opt to produce spatial maps of their biomass stocks, using field-calibrated remote sensing observations. No current satellite can directly estimate aboveground biomass (AGB), so proxies related to forest canopy colour, seasonality parameters, elevation, or the canopy structure are used to estimate and spatially model AGB [10-14].

Two recent maps have been published using this approach to estimate biomass across the tropics at a $1 \mathrm{~km}$ resolution [15], subsequently described as 'RS1', and a $463 \mathrm{~m}$ resolution [16], 'RS2'. These resolutions are considered high enough to be used by carbon forestry projects [9]. Both maps use spaceborne LiDAR data from the Geoscience Laser Altimeter System (GLAS) as samples of forest structure distributed across the tropics, but the two approaches use a different method to extend the isolated GLAS footprints to full-coverage AGB maps. The differences can be summarized as follows:

i) GLAS datasets: Both studies independently downloaded, processed and filtered the GLAS dataset for cloud and slope effects and other potential artefacts. In $R S 1$, filters were introduced to remove all GLAS shots over slopes > 20\% and ground elevations with $>100 \mathrm{~m}$ difference from a global digital elevation model, the Shuttle Radar Topography Mission (SRTM) data at $90 \mathrm{~m}$ resolution; in $R S 2$, the filter removed all GLAS shots that differed from SRTM elevation by $>25 \mathrm{~m}$. In both cases this was done because forest height estimates over sloped terrains may have large biases, causing overestimation of the estimated tree height. Both methods included a series of filters based on the shape of the waveform and the signal-to-noise ratio.

ii) Estimating AGB from GLAS using field plots: Field plots are used to convert millions of individual LiDAR waveforms collected by the GLAS sensor with an approximately $65 \mathrm{~m}$ footprint into AGB estimates. RS1 uses a two-stage process, first building a model to predict Lorey's height (basal-area weighted height) from the LiDAR waveforms using 295 field plots located under GLAS footprints in South America [17], and then deriving three separate continental equations relating Lorey's height to AGB 
using a set of 493 field plots [15]. The AGB values for the field plots are derived from the 3-parameter tropical forest allometric equations including tree diameter, wood density, and height from [18]. The field plots were distributed over three continents, had sizes ranging from 0.2 to 1.0 ha, with the majority of plots being at least $0.25 \mathrm{ha}$, and included all trees $>10$ $\mathrm{cm}$ in diameter measured above buttresses.

RS2 instead builds a model directly relating GLAS waveform characteristics to AGB from 283 calibration field plots located under GLAS footprints [16]. The plots are $40 \mathrm{~m} \times 40 \mathrm{~m}(0.16 \mathrm{ha})$ in size and include all trees $>5 \mathrm{~cm}$ in DBH. Unlike RS1, in RS2, the field data are converted to AGB using allometric equations without tree height from the same study [18]: RS1 uses the 3-parameter equation, whereas $R S 2$ uses the 2-parameter equation, including diameter and wood density but excluding height. The conversion of the GLAS data to AGB in both approaches ignores the potential variations of forest wood density over the landscape and at regional scales: while biomass estimation of the plot data for both maps was based on equations that included wood density as one of the independent variables, the functions that related the GLAS data to the plot-based biomass estimates did not include any parameter to reflect the spatial variability of wood density.

iii) Creation of training and test datasets from

GLAS: For RS1, GLAS AGB estimates are only used in creating the map if at least 5 LiDAR footprints fall within the same $1 \mathrm{~km}$ pixel; this gave 160,918 pixels (with the AGB estimate for each the average of at least 5 LiDAR footprints) for use in training and testing the AGB prediction model. For RS2 GLAS AGB estimates were used if more than 5 footprints were located in a $463 \mathrm{~m}$ pixel for America and Africa, and 3 or more for Asia, giving 58,476 pixels available for training and testing.

iv) Additional training dataset from field plots: Additionally for RS1 4,079 field plots were included in the model although, as these were clustered, they were averaged if multiple plots occurred within the same $1 \mathrm{~km}$ pixel, reducing the total to 1,877 pixels. No field dataset was used directly for training or testing of $R S 2$.

v) Creating continuous AGB maps: The point AGB estimates were averaged to give single AGB estimates at the pixel level, then extrapolated across the full pantropics using visible- and infra-red spectrum optical data from the Moderate Resolution Imaging Spectroradiometer (MODIS) sensors, elevation data from SRTM, and in the case of RS1, QUIKSCAT scatterometer data. The precise MODIS data layers used and cloud filtering applied differ considerably between the studies, with $R S 1$ using Leaf Area Index (LAI) and the Normalised Difference Vegetation Index (NDVI), and RS2 using all the land bands excluding the blue band from the Nadir Bidirectional Reflectance Distribution Function-Adjusted Reflectance (BRDF), the Enhanced Vegetation Index (EVI2), the Normalized Difference Infrared Index (NDII2), and the MODIS Land Surface Temperature products. The extrapolation of biomass is performed using nonlinear, non-parametric models, Maxent in RS1 and Random Forest in RS2, with in both cases a percentage of input data held back for testing (40\% for $R S 1,10 \%$ for $R S 2$ ).

vi) Uncertainty estimates: RS1 additionally produced a spatial uncertainty map, giving an error estimate for every pixel, through bootstrapping the input ground and LiDAR datasets and propagating errors through the model. RS2 estimated uncertainty at the dataset and country level using a Monte Carlo approach.

Here we present a detailed comparison of the outputs of both maps, both directly at the pixel level, and in aggregate over different landcover type classes and countries. However, while comparisons between the maps are interesting, they are of limited use in either confirming the validity of the mapping approach, or stating whether one map should be used preferentially to the other. We cannot use comparisons to field plots to provide these assessments for two reasons: first, the vast majority of well-geolocated recent scientific field plots known to the authors were used in one or other of the maps; and second, all field plots are very much smaller than the pixel size of the maps, and thus only useful in showing if there is large divergence between the maps and ground data, not in providing a quantitative accuracy assessment [19]. We therefore compare the maps to two entirely independent, large-scale ancillary AGB datasets: the country biomass stocks from the FAO Forest Resource Assessment (FRA) estimates [20], and a high resolution $(100 \mathrm{~m})$ LiDAR-derived map for a 16.5 million hectare region of the Colombian Amazon (RS3) [21].

\section{Results and discussion}

Direct comparison of the pantropical biomass maps

Summing the RS1 and RS2 maps by continent gives similar mean and total values (Table 1), with the RS1 carbon stock estimates across the tropics about 10\% lower than $R S 2$, driven mostly by an $18 \%$ difference in tropical Latin America. However, much more dramatic differences are seen when the two maps are compared visually (Figure 1). Absolute differences are most pronounced over tropical forest areas: $R S 1$ estimates are 
Table 1 Mean and total biomass stocks by continent

\begin{tabular}{|c|c|c|c|c|c|}
\hline \multirow[t]{2}{*}{ Continent } & \multicolumn{2}{|c|}{ RS1 [15] } & \multicolumn{2}{|c|}{ RS2 [16] } & \multirow{2}{*}{$\begin{array}{l}\text { Area compared } \\
\left(\mathrm{km}^{2}\right)\end{array}$} \\
\hline & $\begin{array}{c}\text { Mean } \\
\left(\mathrm{Mg} \mathrm{ha}^{-1}\right)\end{array}$ & $\begin{array}{l}\text { Total } \\
(\mathrm{PgC})\end{array}$ & $\begin{array}{c}\text { Mean } \\
\left(\mathrm{Mg} \mathrm{ha}^{-1}\right)\end{array}$ & $\begin{array}{l}\text { Total } \\
\text { (PgC) }\end{array}$ & \\
\hline Africa & 50.8 & 56.2 & 58.4 & 64.5 & $22,105,436$ \\
\hline Americas & 129.8 & 95.5 & 158.1 & 116.3 & $14,713,658$ \\
\hline Asia & 160.2 & 51.7 & 144.9 & 46.8 & $6,457,241$ \\
\hline \multirow[t]{2}{*}{ Pan-tropics } & 94.0 & 203.4 & 105.2 & 227.6 & $43,276,334 \mathrm{~km}^{2}$ \\
\hline & $\mathrm{Mg} \mathrm{ha}^{-1}$ & $\mathrm{PgC}$ & $\mathrm{Mg} \mathrm{ha}^{-1}$ & $\mathrm{PgC}$ & \\
\hline
\end{tabular}

Comparison of the mean and total aboveground biomass (AGB) stocks estimated for continental regions covered by the two maps. See Figure 1 for areas compared: these do not include whole continents but only extend from the Tropic of Cancer to the Tropic of Capricorn. Many areas mapped in RS1 (including Australia, southern Latin American and southern Africa) are not included in $R S 2$, and are thus excluded from the above table. Water bodies are excluded. considerably lower in the central and western Amazon, central and eastern Congo basin, and southern Papua New Guinea, whereas conversely RS2 has lower estimates in the south-eastern Amazon, the western Congo basin, and parts of South-East Asia. Large differences are also visible over woodland and savanna vegetation, but with more consistency: in general $R S 2$ estimates are higher than RS1 in mid- and low- biomass vegetation (with some exceptions, e.g. Kenya and Ethiopia).

Comparing histograms of the biomass distributions shows that the differences are not consistent between continents (Figure 2). In Latin America both RS1 and RS2 have clear bimodal distributions, but the distributions differ markedly between the two datasets. Both peaks are offset to lower values for $R S 1$ compared to $R S 2$, with the savanna (cerrado) peak dominated by values between 10

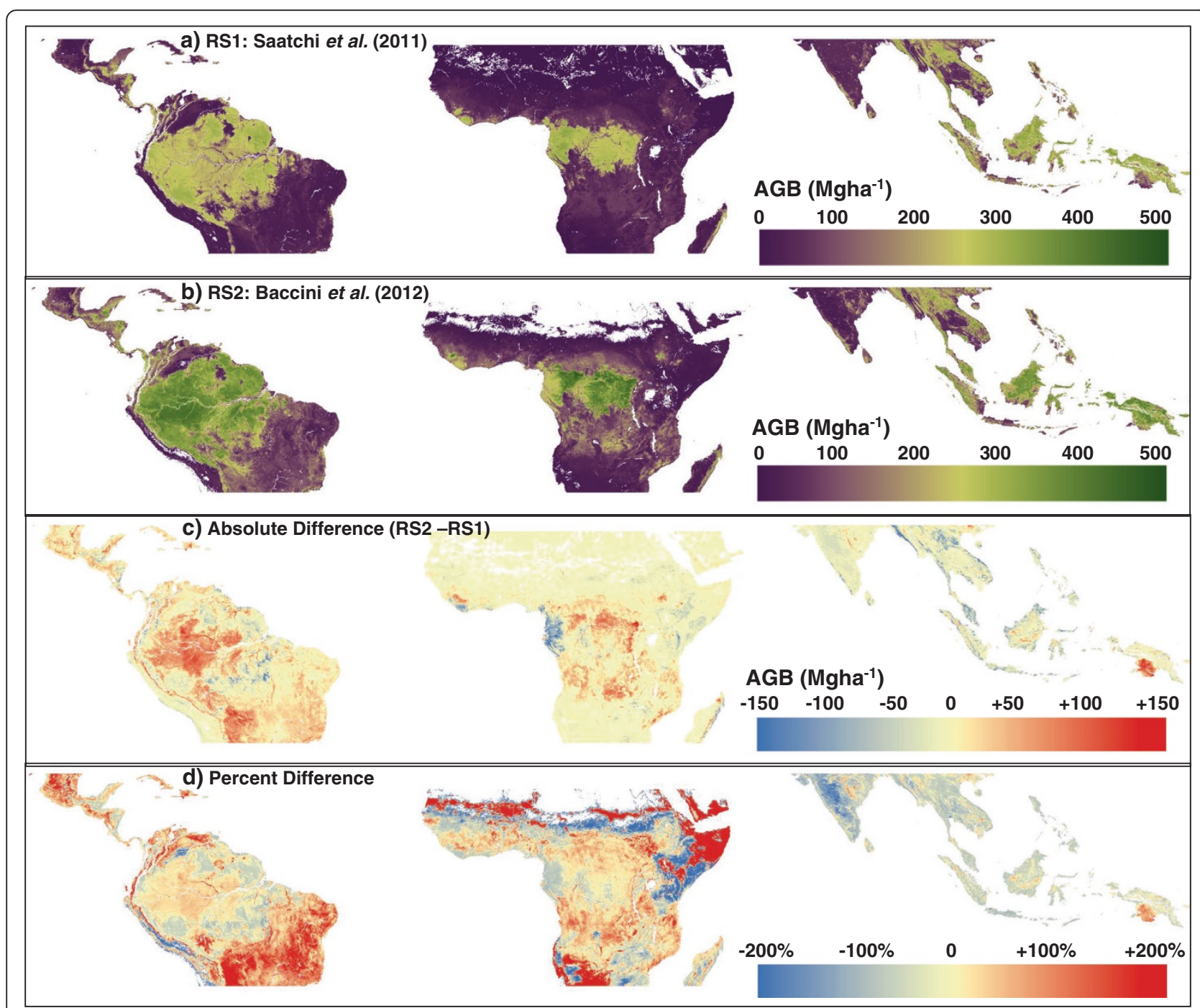

Figure 1 A comparison of two remote sensing based maps of aboveground biomass (AGB) across the tropics: a) AGB for RS1 [15]; b) AGB for RS2 [16]; c) absolute difference, RS2-RS1; d) the percent difference between $R S 2$ and $R S 1$. The projection is sinusoidal, an equal area projection. 


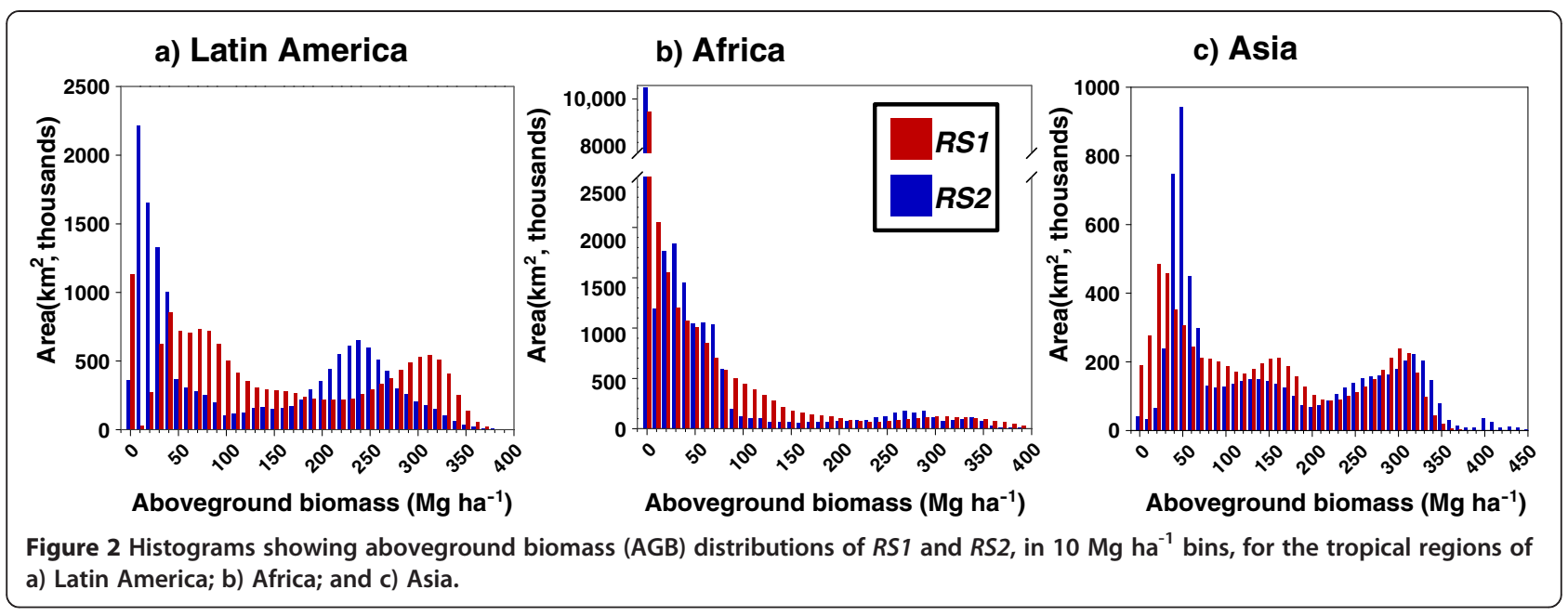

and $50 \mathrm{Mg} \mathrm{ha}^{-1}$ in $R S 1$ and $30-100 \mathrm{Mg} \mathrm{ha}^{-1}$ in $R S 2$, and the tropical forest peak centred around $240 \mathrm{Mg} \mathrm{ha}^{-1}$ in RS1 and $310 \mathrm{Mg} \mathrm{ha}^{-1}$ in RS2. The distributions for Africa are closer to negative-J distributions, with the dominance of grassland and savanna resulting in a much higher frequency of low biomass classes than high biomass classes. However the differences between RS1 and RS2 in Africa are consistent with those in Latin America: once again there is bimodality, and in both cases the peaks are shifted to the left in $R S 1$ compared to $R S 2$. The rainforest peaks are more similar to each other in Africa than in South America, with the clearest difference being the much higher frequency of 90 to $170 \mathrm{Mg} \mathrm{ha}^{-1}$ in RS2 than RS1. The picture is different again in Asia, with biomass appearing to be trimodally distributed in both datasets. In Asia, in contrast to the others, there is evidence that the lowest biomass peak is shifted towards higher biomass values in $R S 1$ compared to $R S 2$, though it may be that this peak occupies a wider range in $R S 2$; the intermediate peak has higher values in $R S 2$ than $R S 1$ throughout; and the high biomass peak has a similar shape and position in both distributions.

\section{Comparison by vegetation class}

Subsetting the biomass distribution using a vegetation map shows that differences are not consistent among classes or continents (Figure 3, Additional file 1: Table S1). There are no large outliers, with no points particularly far from the 1:1 line, but in general again $R S 1<R S 2$ in Africa and Latin America, and RS1 > RS2 in Asia. Looking across the dataset the largest absolute differences are in the "Deciduous broadleaved closed forest", "Needle-leaved evergreen forest", "Regularly flooded shrub" and "Closedopen evergreen shrub" classes, all of which differ by greater than $34 \mathrm{Mg} \mathrm{ha}^{-1}$. Some important classes, for example "Broadleaved evergreen forest", differ in the sign of their difference between continents: RS1 is smaller than
RS2 by $18.7 \mathrm{Mg} \mathrm{ha}^{-1}$ and $30.4 \mathrm{Mg} \mathrm{ha}^{-1}$ in Africa and Latin America respectively, but greater in Asia by $15.8 \mathrm{Mg} \mathrm{ha}^{-1}$. This is a relatively consistent pattern, with 5 of 15 classes having $R S 1<R S 2$ in African and Latin America, but RS2 > RS1 in Asia.

We find no obvious link between the different spatial distribution of field training plots used in the two datasets (which are mostly located in intact tropical forest, with some located in tropical savanna woodland) and the degree of difference between the corresponding vegetation classes. For example there is a large difference in the class best sampled in both datasets ("Tree cover,

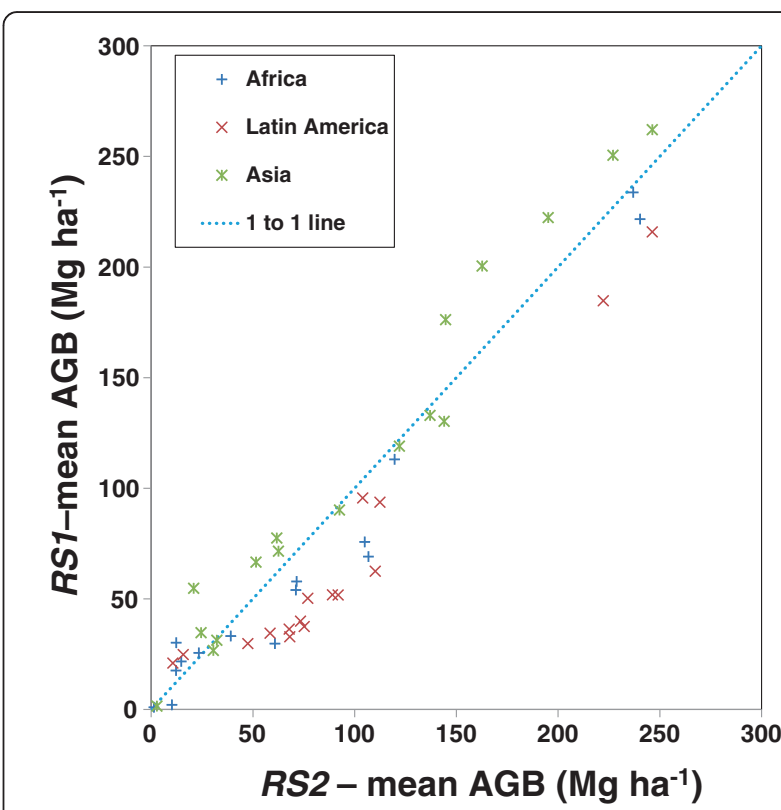

Figure 3 Mean aboveground biomass (AGB) of vegetation classes from the Global Land Cover 2000 dataset [34], split by continents, between RS1 and RS2. The full data are included in Additional file 1: Table S1. 
broadleaved, evergreen"), and a comparatively small difference for "Tree Cover, regularly flooded, saline water", a class which was not included in the LiDAR calibration datasets of either map, and that is known to have a distinct vegetation structure.

\section{Comparison by country total}

Comparisons at a country level show much greater levels of agreement between the maps (Figure 4a-b, Additional file 2: Table S2). In terms of the total biomass for a country, convergence is expected as the area term is identical across both maps. However, more surprisingly, there is also a good deal of convergence in mean AGB across countries. In both cases performing Reduced Major Axis regressions (appropriate as the errors should be equally distributed on both axes) produced best fit lines that were significantly different from the 1:1 line at the 95\% confidence level, with $95 \%$ confidence intervals for slopes ranging from 0.88-0.94 for country stocks, and 0.96-0.99 for mean biomass, suggesting RS1 does on average predict

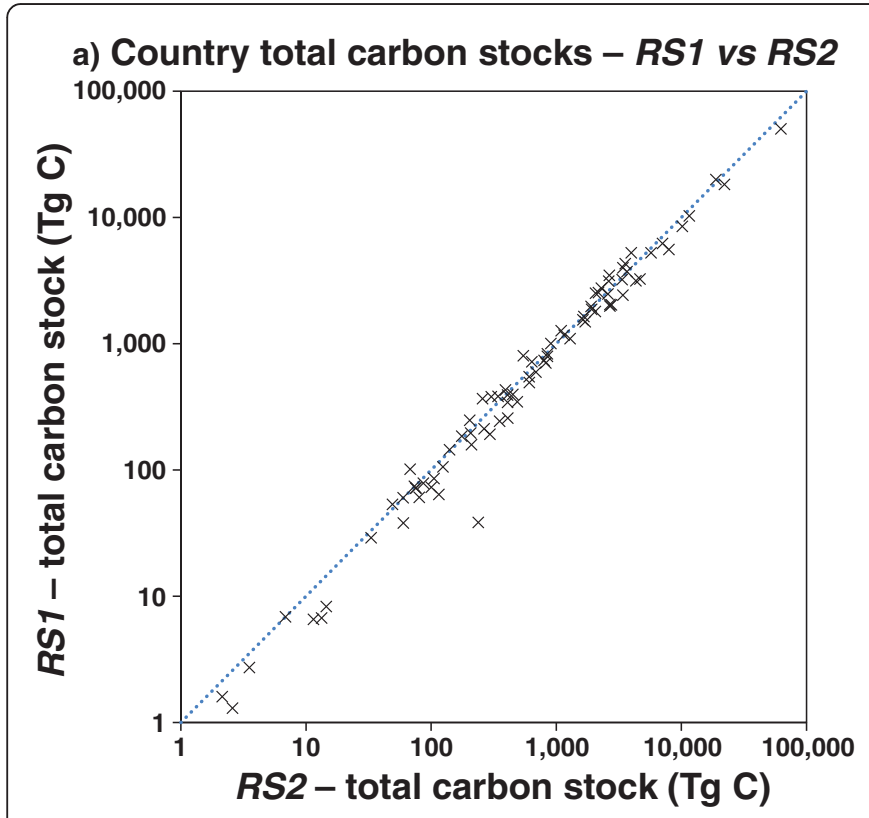

c) Country total carbon stocks - RS vs FRA
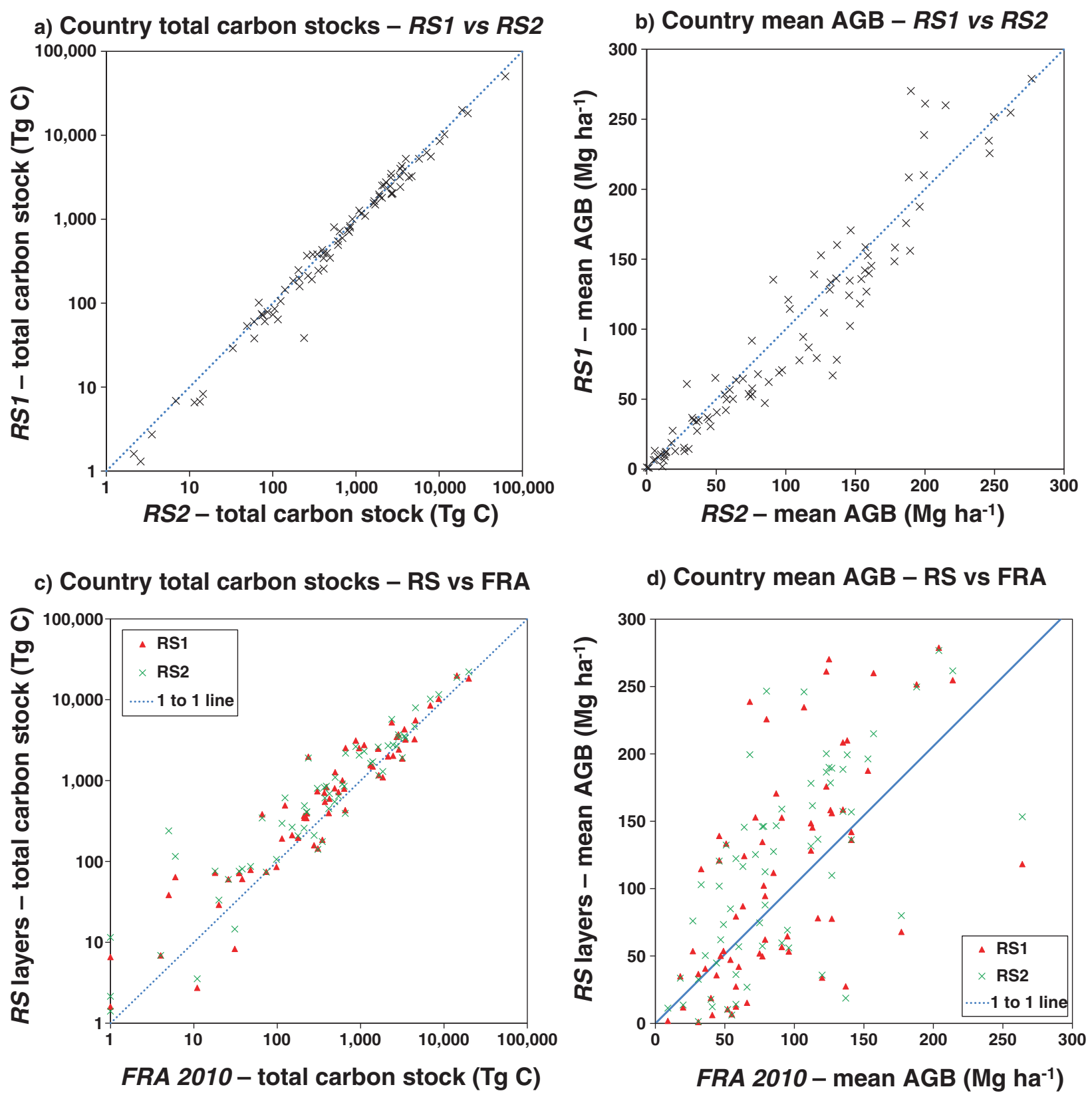

Figure 4 A comparison of carbon stocks and mean aboveground biomass (AGB) values by country for RS1, RS2 and the FAO Forest Resource Assessment (FRA) 2010: a) Country total carbon stocks - RS1 vs RS2; b) Country mean AGB - RS1 vs RS2; c) Country total carbon stocks - RS1 \& RS2 vs FRA; d) Country mean AGB - RS1 \& RS2 vs FRA. 
significantly lower AGB than RS2. However, the r-squared values for the RMA regression lines were 0.97 for total country stocks and 0.91 for mean values, suggesting that there is a strong positive relationship between the datasets. There were some significant outlier countries however, for example Haiti, Gambia and Botswana were estimated as containing $80 \%, 76 \%$ and $60 \%$ more carbon using $R S 2$ than RS1, whereas by contrast East Timor, Kenya and Equatorial Guinea are estimated as containing 49\%, 47\% and 42\% more biomass in RS1 than RS2 (Additional file 2: Table S2). Another way to look at this dataset is to calculate the Root Mean Squared Error (RMSE) in mean carbon stocks between the countries; this value is $23.1 \mathrm{Mg}^{-1}$ when comparing $R S 1$ and $R S 2$ for the 92 countries (Table 2).

While the differences in total biomass for some countries are still very significant, for the majority the two maps agree very well: the mean absolute percentage difference between the two estimates is $12.6 \%$, and the median $8.7 \%$. It seems that the large differences seen in some vegetation classes tend to average out to a certain extent across a country.

\section{Reasons for differences between the biomass maps}

There are many potential explanations for the differences between these maps, but we here highlight the five we believe are the most likely to be responsible:

i) The lower estimates found on average in RS1 over $R S 2$ are most likely to be caused by the different allometric equations used to estimate biomass from the ground plots. Though the equations used in both studies came from the same study [18], RS1 used the 3-parameter models involving height as well as diameter and wood density, where RS2 used the 2-parameter models involving diameter and wood density only. Using a non-varying diameter to tree height allometry has been shown to cause a 10-20\% overestimate in total biomass, [22]. This also explains the continental differences, as the overestimation using a 2-parameter equation should be strongest in South America, which has the shortest trees, and weakest or reversed in SE Asia, which has the tallest trees; this is exactly what is seen in our comparison (Table 1). The average biomass estimates for the 3-parameter model are about 66 $\mathrm{Mg} \mathrm{ha}^{-1}$ lower than the 2-parameter model over intact Amazonian forest, approximately the same magnitude observed in differences between the two maps in various regions of Amazonia [22]. Although the allometry may introduce a bias between the two maps, the magnitude of bias will have spatial patterns depending on forest types and regional differences in forest structure and allometry [22].

ii) The methodology used in processing and filtering the GLAS LiDAR data may have caused some differences in the height values used in training the spatial modelling of biomass. In both cases GLAS data were filtered if they differed significantly from the SRTM dataset, but only in RS1 were the data filtered based on slope and signal-to-noise ratio. In both cases pixels were only used for training if at least five GLAS footprints were located within them, and the AGB values from the GLAS footprints were averaged (except for $R S 2$ in SE Asia, where the criteria was relaxed to greater than or equal to three footprints); this averaging process will reduce noise and to a certain extent smooth out differences in processing, but residual biases from this process could be carried through into the maps.

iii) Different data layers were used to extrapolate the two datasets. RS1 used QUIKSCAT radar data in addition to layers similar to those used in $R S 2$, whereas $R S 2$ was driven primarily by MODIS and topography data. Equally RS2 used bidirectionally corrected reflectance (BRDF), EVI2, NII2 and Land Surface Temperate MODIS layers, whereas RS1 used the seasonal LAI and NDVI MODIS layers. These layers contain different spatial information, and thus despite the use of similar GLAS data, it is likely that these differences changed the spatial patterns in the derived products. Note that none of the data layers used to capture the variations of forest biomass are sensitive to the range of biomass values found in tropical forests and often saturate at low biomass values.

Table 2 Comparison of mean biomass stocks and RMSE values for countries by continent

\begin{tabular}{|c|c|c|c|c|c|c|c|}
\hline \multirow[t]{3}{*}{ Continent } & \multicolumn{3}{|c|}{ Mean country AGB } & \multicolumn{3}{|c|}{ RMSE for country mean AGB } & \multirow{3}{*}{$\begin{array}{l}\text { Number } \\
\text { countries } \\
\text { compared }\end{array}$} \\
\hline & RS1 & RS2 & FRA2010 & $R S 1$ vs $R S 2$ & & RS2 vs FRA2010 & \\
\hline & $\left(\mathrm{Mg} \mathrm{ha}^{-1}\right)$ & $\left(\mathrm{Mg} \mathrm{ha}^{-1}\right)$ & $\left(\mathrm{Mg} \mathrm{ha}^{-1}\right)$ & $\left(\mathrm{Mg} \mathrm{ha}^{-1}\right)$ & $\left(\mathrm{Mg} \mathrm{ha}^{-1}\right)$ & $\left(\mathrm{Mg} \mathrm{ha}^{-1}\right)$ & \\
\hline Africa & 68.9 & 74.2 & 83.4 & 25.0 & 54.8 & 44.3 & 37 \\
\hline Americas & 113.8 & 130.2 & 99.0 & 20.8 & 50.4 & 63.5 & 28 \\
\hline Asia & 157.1 & 142.2 & 99.0 & 27.5 & 102.4 & 85.7 & 14 \\
\hline Pantropics & 100.5 & 106.1 & 91.0 & 24.1 & 65.0 & 59.7 & 79 \\
\hline
\end{tabular}

Comparison of mean aboveground biomass (AGB) and Root Mean Square Error (RMSE) between estimates at a country level, using only countries where there is complete coverage in both RS1 and RS2. Country-level data available in Additional file 2: Table S2. 
iv) Different modelling environments were used to extrapolate the LiDAR-derived training data: Maxent in RS1, and Random Forest in RS2. Random Forest is widely used across a wide range of fields for classification and regression, and its bias and error characteristics are well understood [23,24]. Maxent is also widely used, especially for classification and species distribution modelling [25], though it is less commonly used, and therefore less well understood, for modelling continuous variables such as AGB. It is likely that this choice of algorithm explains some of the differences in spatial patterns. Both models are considered nonparametric and depend strongly on the statistical approach that optimizes the extrapolation of the training data when the sensitivity of image data layers to biomass is low. In general, Random Forest performs better in capturing the mean statistics of the training data, but may suffer from overfitting the training data: as a sign of this Random Forest tends to produce considerably higher accuracies against training than test data. Maxent, on the other hand, works with probabilities of estimating a class of biomass range, and thus does not necessarily produce a result with a similar mean to the input data, but should produce predictions without overfitting. This leads to Maxent producing estimates with similar errors in both training and independent test data, though these errors may be large. In the absence of any global satellite observation of forest structure and biomass all extrapolations will be a compromise between accuracy and overfitting, and only more independent verification datasets will allow for selection of the 'best' model.

v) Due to mixed input layers neither map is truly a single date product, nevertheless dates of the two maps differ: $R S 1$ is dated 'early 2000's', and RS2 '2007'. There has been significant land use change across the tropics over this period [3], so it is possible that some of the differences seen could be due to land-use change. However, this cannot explain the large differences in relatively undisturbed areas, for example central Amazonia, nor the many areas where $R S 1$ is greater than $R S 2$.

vi) Some additional differences could be due to the different pixel sizes used: $463 \mathrm{~m}(R S 2)$ vs. $1 \mathrm{~km}$ (RS1). Larger pixel sizes result in a smaller range of biomass values, due to spatial averaging, and the exclusion of very high biomass values due to landscape heterogeneity. This difference should be especially apparent in the histogram comparisons: RS2 should have a wider distribution than RS1, all else being equal, simply because its input pixel size is a quarter of that of RS1. We performed the analysis at the higher resolution, that of RS2, in order to avoid introducing artefacts by changing pixel values in either dataset. However, as a test, we also reduced the resolution of RS2 to that of RS1 and produced histograms to see if this could be part of the cause of the difference. The histogram results were nearly identical, with the size of every bar within $2 \%$ of the size at full resolution, so while resolution could be a factor in the differences observed, it is not the main cause.

\section{Comparison with FAO 2010 Forest Resource Assessment}

There is less convergence when comparing the RS1 and RS2 maps to the FRA 2010 estimates than to each other (Figure 4c-d, Table 2, Additional file 2: Table S2). The RMSE values for the comparison of the mean country totals of each map with the corresponding values from the FRA dataset are 2-3 times higher than the comparisons directly between the two maps (Table 2). This is not surprising given the very different methodologies used, and the limited capacity of many tropical countries to perform such assessments [26]. However, there is still a significant positive relationship for the mean estimates, and the country totals are remarkably close, particularly for large countries (Figure 4c).

In general the remote sensing maps estimate higher mean AGB values than the FAO values. This is surprising, as the FAO values are reported for forest areas only (the FAO forest definition includes lands with $>10 \%$ crown cover and also includes plantations), whereas the estimates based on $R S 1$ and $R S 2$ include all land, including that not officially classed as 'forest'. The exception to this is Africa where in general FRA 2010 estimates are higher than either $R S 1$ or $R S 2$ (Table 2, Additional file 2: Table S2). This is probably due to the larger proportion of non-forest vegetation in these countries, which brings down the average for the $R S$ layers but is ignored by the FRA 2010. This is supported by lack of bias in the total country stocks.

\section{Comparison with a high resolution airborne LiDAR map of Colombia}

We compared the pantropical RS maps (RS1 and RS2) to a recently published AGB map of $165,000 \mathrm{~km}^{2}$ of Colombia (RS3), derived from field-plot calibrated aircraft LiDAR for $2.8 \%$ of the area extrapolated to the region through stratification using optical satellite data, historical forest-change data, and a digital terrain model [21]. RS3 is expected to have high accuracy $( \pm 28 \%$ for any given 1 ha pixel) due to its reliance on locallycalibrated high resolution LiDAR data. There are large differences visible between the maps when compared visually (Figure 5), though the broad distribution of biomass is preserved: $R S 3$ has lower estimates throughout 

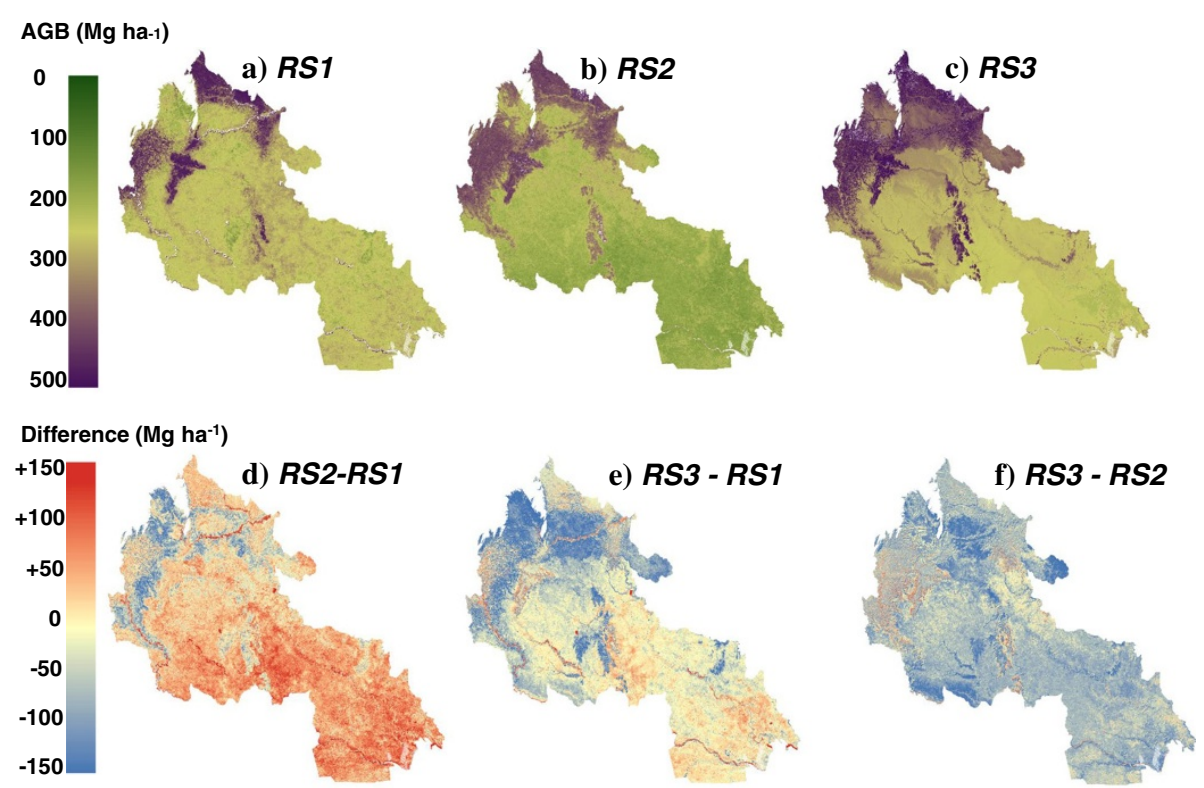

Figure 5 A comparison of aboveground biomass (AGB) in three remote sensing maps and differences between them for the region of Amazonian Colombia covered by $R S 3$ [21]: a) $R S 1$, b) $R S 2$, c) $R S 3$, d) $R S 2$ - RS1, e) $R S 3$ - RS1, f) $R S 3$ - RS2.

the region, and in particular much lower in the higher elevation areas in the north. The total aboveground carbon stocks differ considerably: RS1 estimates stocks $23 \%$ higher than RS3, and RS2 42\% higher (Table 3).

When comparing the histograms (Figure 6) a more complex picture appears. There appears to be a very close match between $R S 1$ and RS3, with the high biomass peak for $R S 2$ offset approximately $90 \mathrm{Mg} \mathrm{ha}^{-1}$ to the right (similar to Figure 2a comparing $R S 1$ and $R S 2$ for Latin America). However both $R S 1$ and $R S 2$ extend to higher values than RS3: the highest value for RS3 is $283.3 \mathrm{Mg} \mathrm{ha}^{-1}$, whereas it is $435.7 \mathrm{Mg} \mathrm{ha}^{-1}$ and $387.0 \mathrm{Mg}$ $\mathrm{ha}^{-1}$ for $R S 1$ and $R S 2$ respectively. It is this lack of high values and low estimates in the mountainous regions that explain the low total carbon stock value for RS3.

These biomass differences can be explained by a combination of six different factors.

i) $R S 3$ uses the same allometry as $R S 1$, whereas $R S 2$ uses an allometry excluding height that results in an overestimate of total AGB by $10-20 \%$ [22].

Table 3 Mean and total biomass stocks for a 16 million hectare subset of the Colombian Amazon

\begin{tabular}{lcc}
\hline Layer & \multicolumn{2}{c}{ Biomass stocks } \\
\cline { 2 - 3 } & Mean $\left(\mathbf{M g ~ h a}^{-1}\right)$ & Total $(\mathbf{P g C})$ \\
\hline RS1 [15] & 218.1 & 1.806 \\
RS2 [16] & 252.0 & 2.087 \\
RS3 [21] & 183.4 & 1.473 \\
\hline
\end{tabular}

Comparison of the mean and total biomass stocks for a 16,561,695 ha area of the Colombian Amazon mapped in detail at high resolution (100 m) by RS3. ii) Wood density: RS3 uses local wood density, whereas RS1 effectively uses South America mean wood density information (contained within its continental Lorey's height to AGB relationship), and RS2 uses a mean wood density information across the tropics, contained within the allometries in training data used to develop its pantropical GLAS to AGB relationship. Thus the lower AGB values in RS3 could be due to especially low wood density in this area.

iii) The relationship between tree diameter and height varies with elevation, soil fertility and geographic location: all three maps treat DBH-height equations differently, with effectively a single equation used for all of South America in RS1 due to the use of a single Lorey's height to AGB equation, a single equation for the whole tropics in RS2 due to the use of an allometric equation that does not include height, and a locally-derived equation for RS3. If trees in this region are comparatively short for their diameter, as suggested by the data in [21], then that would explain the lower AGB estimate for RS3 compared to the other datasets.

iv) Different dates: there may have been significant deforestation in between the creation of the pantropical maps, which have nominal dates of 'early 2000's' (RS1) and approximately 2007 (RS2), and the RS3 acquisition in 2011.

v) The different resolutions of the three studies, in particular the much higher $100 \mathrm{~m}$ resolution of $R S 3$, could be influencing the results. It is known that forest biomass scales in a complex manner with resolution, even in a non-heterogeneous landscape [27]. 


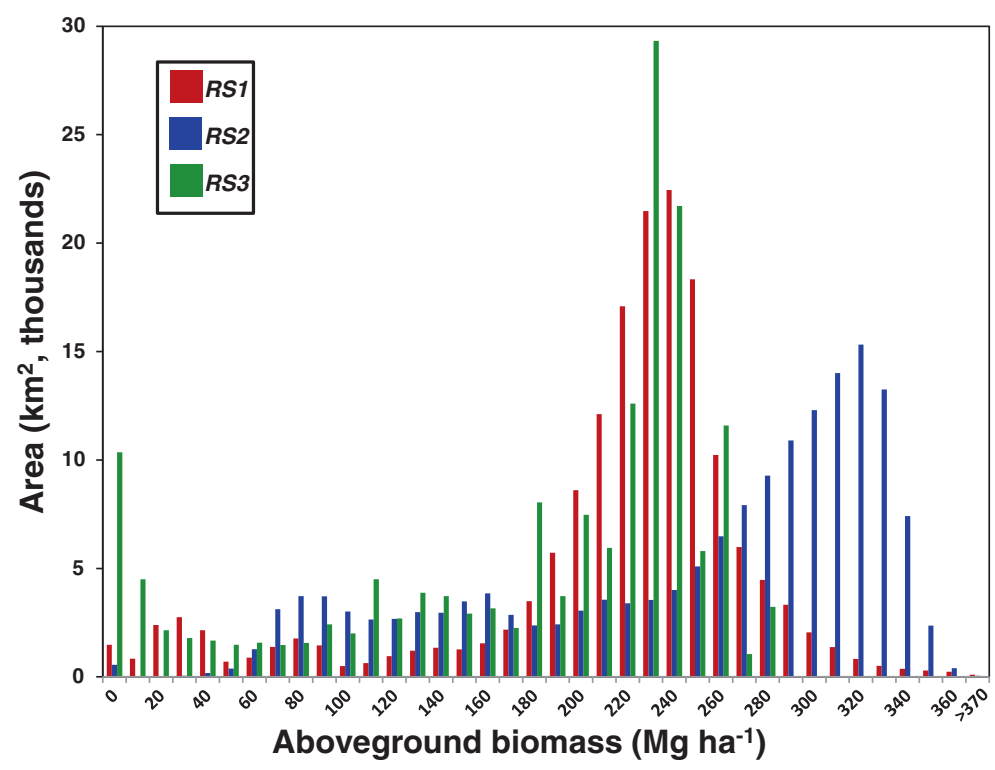

Figure 6 Histogram showing the aboveground biomass AGB distribution of RS1, RS2 and RS3 over the region of Amazonian Colombia covered by RS3, with $10 \mathrm{Mg} \mathrm{ha}^{-1}$ bins.

vi) Errors in the extrapolation procedure between LiDAR flight paths and the wider region in RS3, in particular the prediction of low biomass values at high elevation areas in the north, and the lack of high biomass values in the densest forest areas, could be erroneous. This final possibility is supported as an alternative map produced in the same study using the same input data but a different spatial extrapolation technique (regression with elevation and the fractional cover of photosynthetic vegetation, rather than a stratification with the same variables plus vegetation history and terrain ruggedness) predicts much higher biomass values in the northern, high elevation areas; and that the field data used to calibrate the LiDAR regression equation has plots with biomass values above $300 \mathrm{Mg} \mathrm{ha}^{-1}$, but no pixels in the resulting map exceed $283.3 \mathrm{Mg} \mathrm{ha}^{-1}$.

Thus though RS3 provides an independent test of the pantropical maps, and the comparison is interesting, there are too many uncertainties involved for it to provide validation of one map over the other.

\section{Conclusions}

We found that RS1 and RS2 differ significantly in their AGB estimates over a wide variety of forest cover types and scales; however at country level there is general agreement, with much of the country-level difference explained by the choice of different allometric equations. This has an important implication for REDD+ - it appears we have the algorithms and tools to estimate biomass stocks with some certainty, and the largest uncertainties in setting up deforestation baselines relate to forest cover changes (rates of deforestation/degradation) [3,28].

When summed to a regional scale, RS2 estimates on average higher biomass values than $R S 1$. This is almost certainly due to the different choice of allometric equations, with the 2-parameter equations excluding height used in RS2 known to consistently estimate higher biomass values than the 3-parameter equations including height used by RS1 [22]. Further differences between the layers could be due to a variety of factors, including their different ground and remote sensing input data, different modelling environments, and different pixel sizes. It is also clear from comparison to a high resolution, locally calibrated map (RS3) that a further limitation present in both studies is the lack of local wood density or diameterheight calibration. Both are known to vary considerably across the landscape $[22,29]$ but the use of a single (RS2) or three continental (RS1) equations relating GLAS LiDAR footprints to AGB smooths out these variations.

All three remote sensing maps compared here actually use a very similar processing chain to produce their AGB maps, despite the difference in scale and resolution between the pantropical maps (RS1 and $R S 2$ ) and the regional map (RS3). They all use LiDAR data to produce distributed estimates of canopy height (ICESat GLAS for RS1 and RS2, aircraft LiDAR for RS3), convert these to AGB using field data located under the LiDAR footprints and generic allometric equations, and then use these points to train model biomass across the landscape using ancillary data layers, including optical satellite data and terrain information. This method makes intrinsic sense, balancing the cost to accuracy trade-off of field, 
LiDAR and optical data, and should produce internally consistent products that can be validated against independent field datasets. Such a processing chain could be followed by most projects attempting to create baseline carbon maps, and adapted to reflect existing input data available, and the required accuracy. There has been little work as yet on the uncertainties associated with differencing products produced in this way for different years to assess changes due to deforestation, degradation, and forest growth: as REDD+ payments are effectively based on differences in carbon stocks, it is important that further work is done in this area.

Quantifying emissions from deforestation has largely made use of simple book-keeping models based around FAO and IPCC data [1,30], and more recently explicit carbon maps to quantify stocks before deforestation at a pixel level [3]. The results here support the latter approach: it is clear that carbon stocks vary greatly within the forests of every country, and that is important because deforestation within a country is also not evenly distributed. For this reason information on the spatial distribution of stocks would be expected to improve upon estimates based strictly on sampling approaches.

Currently the carbon stocks for a region or country are often based on guideline mean biomass values for particular vegetation types [31] or on country-specific mean carbon stock values, for example from FRA 2010 [20]. These results suggest that pantropical biomass maps can provide much better estimates of carbon stocks at a project or national level, and despite some differences, independent maps show a high level of consistency. We hope that these products, and improvements on them, are widely used. All three maps compared here contain detailed error propagation procedures, and give confidence intervals at both a pixel and regional level $[15,16,21]$. Ultimately the only way to truly quantify the errors on biomass maps of these scales would be to perform the destructive harvest of plots the size of a whole pixel, which is impractical, so these uncertainty estimates are themselves only estimates of the true error. However, error propagation methods for biomass mapping are now well established [9,32], and the relative agreement between all three independent maps, at least at a regional scale, provides some confidence in this procedure.

Despite the general agreement discussed above, we cannot ignore the large differences between the maps in some areas (Figure 1). These tend to be areas where we have the least field data, most notably in central Amazonia, the Congo basin, and Papua New Guinea. Field campaigns, ideally combined with destructive tree harvesting to reduce uncertainties in allometries, and airborne LiDAR to allow for accurate spatial extrapolation across a landscape, would be particularly useful to improve our understanding of the carbon stocks in these regions.

\section{Data preparation \& methods}

We performed all re-projections and subsequent analyses of remote sensing data using IDL-ENVI 4.8 (Exelis VIS), and all area summation calculations using ArcMap 9.3.1 (ESRI). The original AGB datasets (RS1 [15] and RS2 [16]) were provided by the authors in their native projections and resolutions: 0.00833 degrees $($ c. $1 \mathrm{~km})$ and a geographic (WGS-84) projection for RS1, and $463 \mathrm{~m}$ and the MODIS sinusoidal projection for RS2. In order to avoid introducing artefacts by changing the true resolution of either dataset or averaging any pixel values, we warped $R S 1$ to the same projection and resolution as RS2, using a rigorous arithmetic conversion between the projections and a nearest neighbour resampling method (so no pixel values were changed). This had the added advantage that the subsequent analyses all took place in an equal area projection (sinusoidal), simplifying area-summation and averaging calculations. RS3 [21] was provided in a Universal Transfer Mercator (UTM) projection at $100 \mathrm{~m}$ resolution; we reprojected it to the $463 \mathrm{~m}$ MODIS sinusoidal projection of $R S 2$ using a rigorous transformation and cubic convolution for comparative figures, and left it at its native resolution for summation calculations. RS3 was provided in units of $\mathrm{MgC} \mathrm{ha}^{-1}$, so we converted it to $\mathrm{Mg} \mathrm{ha}^{-1}$ (dry biomass), the same units as $R S 1$ and $R S 2$, by dividing by 0.485 , the conversion stated in the paper [21].

We used two vector datasets to subset the AGB maps in different ways. First we queried the data using country outlines from the ESRI Data \& Maps Database, using the World Countries layer updated on $17^{\text {th }}$ January 2012. Second we used the Global Land Cover 2000 (GLC-2000) as a vegetation cover dataset [33]; this dataset has been shown to be globally consistent [34], uses a biologicallyrelevant hierarchical legend based on the FAO Land Cover Classification System, and was used as a core dataset in the Millennium Ecosystem Assessment. Its $1 \mathrm{~km}$ resolution is comparable to the remote sensing datasets.

We compared the different raster layers directly, and through comparison of averages within the vector datasets. We also compared the datasets at a country level to the total carbon estimates from the FAO's 2010 Forest Resource Assessment (FRA) [20]. In all cases we converted dry biomass (the units of RS1 and RS2) to carbon (the units of the FRA) by multiplying by 0.5 (following that used by $R S 1$ and $R S 2$, but differing from the 0.485 used originally in RS3), and carbon to $\mathrm{tCO}_{2} \mathrm{e}$ by multiplying by 3.667 [9].

\section{Data}

The datasets used in this study have been made available by the authors. $R S 1$ is available at http://carbon.jpl.nasa. gov/data/dataMain.cfm, and RS2 at http://www.whrc. org/mapping/pantropical/carbon_dataset.html. 
Additionally the three datasets can be compared interactively at http://carbonmaps.ourecosystem.com.

\section{Additional files}

\begin{abstract}
Additional file 1: A comparison of the mean aboveground biomass (AGB, Mg ha ${ }^{-1}$ ) in different landcover classes from the Global Land Cover 2000 map between RS1 [15] and RS2 [16] by continent and across the tropics. Water bodies are excluded from these calculations. Additional file 2: A comparison of the mean, median, maximum and total carbon stock by country in three datasets: RS1 [15], RS2 [16] and the FAO Forest Resource Assessment (FRA) 2010. The total area of the country within the RS maps is also included: where this is different to the total area of the country the figures are put in italics, and comparisons with the FRA data (which are for the full country) are not valid. Countries have only been included if greater than $50 \%$ of their surface is covered by the RS maps. Water bodies are excluded from these calculations.
\end{abstract}

\section{Competing interests}

The authors declare that they have no competing interests.

\section{Authors' contributions}

The study was devised by EM, SS \& SG. EM performed the analysis and produced the figures using data layers provided by SS, AB and GA. EM wrote the text, with substantial contributions and edits made by all other authors. All authors read and approved the final manuscript.

\section{Acknowledgements}

We acknowledge all the co-authors of $[15,16,21]$, who allowed us to use and compare these data layers, and all the data providers and field assistants who made their production possible.

Edward Mitchard is supported by a Research Fellowship from the Natural Environment Research Council (NE/I021217/1). The Carnegie Institution study in Colombia [21] was supported by the Gordon and Betty Moore Foundation and the Grantham Foundation for the Protection of the Environment. WHRC participation was supported by the Gordon and Betty Moore Foundation, Google.org and the David and Lucile Packard Foundation. Funding for this work was provided to Winrock International under contract 7150484 by the World Bank's World Development Report 2010: Development and Climate Change.

\section{Author details}

'School of GeoSciences, University of Edinburgh, Crew Building, The King's Buildings, Edinburgh EH9 3JN, UK. ${ }^{2}$ Jet Propulsion Laboratory, California Institute of Technology, Pasadena, CA 91109, USA. ${ }^{3}$ Woods Hole Research Center, 149 Woods Hole Road, Falmouth, MA 02540-1644, USA. ${ }^{4}$ Department of Global Ecology, Carnegie Institution for Science, 260 Panama Street, Stanford, CA 94305, USA. ${ }^{5}$ Ecosystem Services Unit, Winrock International, 2121 Crystal Drive, Suite 500, Arlington, VA 22202, USA.

Received: 1 July 2013 Accepted: 17 October 2013

Published: 26 October 2013

\section{References}

1. van der Werf GR, Morton DC, DeFries RS, Olivier JGJ, Kasibhatla PS, Jackson RB, Collatz GJ, Randerson JT: CO2 emissions from forest loss. Nat Geosci 2009, 2:737-738

2. Pan Y, Birdsey RA, Fang J, Houghton R, Kauppi PE, Kurz WA, Phillips OL, Shvidenko A, Lewis SL, Canadell JG, et al: A large and persistent carbon sink in the World's forests. Science 2011, 333:988-993.

3. Harris NL, Brown S, Hagen SC, Saatchi SS, Petrova S, Salas W, Hansen MC Potapov PV, Lotsch A: Baseline Map of carbon emissions from deforestation in tropical regions. Science 2012, 336:1573-1576.

4. Laurance WF: Can carbon trading save vanishing forests? Bioscience 2008 , 58:286-287.

5. UNFCCC: Appendix 1: Guidance and safeguards for policy approaches and positive incentives on issues relating to reducing emissions from deforestation and forest degradation in developing countries; and the role of conservation, sustainable management of forests and enhancement of forest carbon stocks in developing countries. In The Cancun Agreements: Outcome of the work of the Ad Hoc Working Group on Long-term Cooperative Action under the Convention. 2010:26-27. FCCC/CP/ 2010/7/Add1. http://unfccc.int/documentation/documents/advanced_search/ items/6911.php?priref=600006173.

6. Clements GR, Sayer J, Boedhihartono AK, Venter O, Lovejoy T, Koh LP, Laurance WF: Cautious optimism over Norway-Indonesia REDD pact. Conserv Biol 2010, 24:1437-1438.

7. Caravani A, Nakhooda S, Watson C: The Evolving Global Climate Finance Architecture. Heinrich Boll Stiftung: Overseas Development Institute; 2012.

8. Diaz D, Hamilton K, Johnson E: State of the forest carbon markets 2011. In Forest Trends. 2011. http://www.forest-trends.org/publication_details.php? publication $\mid \mathrm{D}=2963$.

9. GOFC-GOLD: A sourcebook of methods and procedures for monitoring and reporting anthropogenic greenhouse gas emissions and removals caused by deforestation, gains and losses of carbon stocks in forests, remaining forests, and forestation. 2009. Version COP15-1 edition. Available at: http://www.gofcgold.wur.nl/redd/.

10. Woodhouse IH, Mitchard ETA, Brolly M, Maniatis D, Ryan CM: Radar backscatter is not a 'direct measure' of forest biomass. Nature Clim Change 2012, 2:556-557.

11. Lu DS: The potential and challenge of remote sensing-based biomass estimation. Int I Rem Sens 2006, 27:1297-1328.

12. Saatchi S, Ulander L, Williams M, Quegan S, LeToan T, Shugart H, Chave J: Forest biomass and the science of inventory from space. Nature Clim Change 2012, 2:826-827.

13. Clark DB, Kellner JR: Tropical forest biomass estimation and the fallacy of misplaced concreteness. J Veget Sci 2012, 23:1191-1196.

14. Goetz S, Baccini A, Laporte N, Johns T, Walker W, Kellndorfer J, Houghton R, Sun M: Mapping and monitoring carbon stocks with satellite observations: a comparison of methods. Carbon Bal Manag 2009, 4:2.

15. Saatchi SS, Harris NL, Brown S, Lefsky M, Mitchard ETA, Salas W, Zutta BR, Buermann W, Lewis SL, Hagen S, et al: Benchmark map of forest carbon stocks in tropical regions across three continents. Proc Natl Acad Sci 2011, 108:9899-9904.

16. Baccini A, Goetz SJ, Walker WS, Laporte NT, Sun M, Sulla-Menashe D, Hackler J, Beck PSA, Dubayah R, Friedl MA, et al: Estimated carbon dioxide emissions from tropical deforestation improved by carbon-density maps. Nature Clim Change 2012, 2:182-185.

17. Lefsky M: A global forest canopy height map from the moderate resolution imaging spectroradiometer and the geoscience laser altimeter system. Geophys Res Lett 2010, 37, L15401.

18. Chave J, Andalo C, Brown S, Cairns MA, Chambers JQ, Eamus D, Folster H, Fromard F, Higuchi N, Kira T, et al: Tree allometry and improved estimation of carbon stocks and balance in tropical forests. Oecologia 2005, 145:87-99.

19. Mitchard ETA, Saatchi SS, Lewis SL, Feldpausch TR, Gerard FF, Woodhouse IH, Meir P: Comment on 'A first map of tropical Africa's above-ground biomass derived from satellite imagery'. Environ Res Lett 2011, 6:049001.

20. FAO: Global Forests Resources Assessment 2010. Rome: FAO Forestry Paper; 2010:163.

21. Asner GP, Clark JK, Mascaro J, Galindo García GA, Chadwick KD, Navarrete Encinales DA, Paez-Acosta G, Cabrera Montenegro E, Kennedy-Bowdoin T, Duque Á, et al: High-resolution mapping of forest carbon stocks in the Colombian Amazon. Biogeosciences 2012, 9:2683-2696.

22. Feldpausch TR, Lloyd J, Lewis SL, Brienen RJW, Gloor M, Monteagudo Mendoza A, Lopez-Gonzalez G, Banin L, Abu Salim K, Affum-Baffoe $K$, et al: Tree height integrated into pantropical forest biomass estimates. Biogeosciences 2012, 9:3381-3403.

23. Strobl C, Boulesteix A-L, Zeileis A, Hothorn T: Bias in random forest variable importance measures: illustrations, sources and a solution. BMC Bioinformatics 2007, 8:25.

24. Prasad A, Iverson L, Liaw A: Newer classification and regression tree techniques: bagging and random forests for ecological prediction. Ecosystems 2006, 9:181-199.

25. Phillips SJ, Dudík M: Modeling of species distributions with Maxent: new extensions and a comprehensive evaluation. Ecography 2008, 31:161-175.

26. Romijn E, Herold M, Kooistra L, Murdiyarso D, Verchot L: Assessing capacities of non-Annex I countries for national forest monitoring in the context of REDD+. Environ Sci Pol 2012, 19-20:33-48. 
27. Chave J, Condit R, Lao S, Caspersen JP, Foster RB, Hubbell SP: Spatial and temporal variation of biomass in a tropical forest: results from a large census plot in Panama. J Ecol 2003, 91:240-252.

28. Bucki M, Cuypers D, Mayaux P, Achard F, Estreguil C, Grassi G: Assessing REDD+ performance of countries with low monitoring capacities: the matrix approach. Environ Res Lett 2012, 7:014031.

29. Chave J, Muller-Landau HC, Baker TR, Easdale TA, Ter Steege H, Webb CO: Regional and phylogenetic variation of wood density across 2456 neotropical tree species. Ecol Appl 2006, 16:2356-2367.

30. IPCC: Contribution of Working Group I to the Fourth Assessment Report of the Intergovernmental Panel on Climate Change. Cambridge: Cambridge University Press; 2007.

31. IPCC: Good Practice Guidance for Land Use, Land-Use Change and Forestry. Geneva; 2003. http:/www.ipcc-nggip.iges.or.jp/public/gpglulucf/gpglulucf.html.

32. Chave J, Condit R, Aguilar S, Hernandez A, Lao S, Perez R: Error propagation and scaling for tropical forest biomass estimates. Philos Trans R Soc Lond A 2004, 359:409-420.

33. Fritz S, Bartholomé E, Belward A, Hartley A, Stibig HJ, Eva H, Mayaux P, Bartalev $S$, Latifovic R, Kolmert $S$, et al: Harmonisation, mosaicing and production of the Global Land Cover 2000 database (beta version). Brussels: European Commissions - Joint Research Centre; 2003.

34. Mayaux P, Eva H, Gallego J, Strahler AH, Herold M, Agrawal S, Naumov S, De Miranda EE, Di Bella CM, Ordoyne C, et al: Validation of the global land cover 2000 map. IEEE Trans Geosci Rem Sens 2006, 44:1728-1739.

doi:10.1186/1750-0680-8-10

Cite this article as: Mitchard et al:: Uncertainty in the spatial distribution of tropical forest biomass: a comparison of pan-tropical maps. Carbon Balance and Management 2013 8:10.

\section{Submit your next manuscript to BioMed Central and take full advantage of:}

- Convenient online submission

- Thorough peer review

- No space constraints or color figure charges

- Immediate publication on acceptance

- Inclusion in PubMed, CAS, Scopus and Google Scholar

- Research which is freely available for redistribution 